\title{
Juvenile dermatomyositis: is periodontal disease associated with dyslipidemia?
}

\author{
Kátia T. Kozu ${ }^{1 *}$, Clovis A. Silva ${ }^{1,2}$, Nadia E. Aikawa², Rosa M. R. Pereira², Adriana M. Sallum', Cynthia Savioli², \\ Eduardo Borba ${ }^{2}$ and Lucia M. Campos ${ }^{1}$
}

\begin{abstract}
Background: Association between periodontal disease and dyslipidemia was recently reported in healthy adults. However, a systematic evaluation of concomitant periodontal diseases and lipid profile was not carried out in juvenile dermatomyositis (JDM).

A cross-section study was performed in 25 JDM patients and 25 healthy controls, assessing demographic data, periodontal evaluation, fasting lipoproteins and anti-lipoprotein lipase antibodies. Disease parameters, laboratorial tests and treatment were also evaluated in JDM patients.
\end{abstract}

Results: The mean current age was similar in patients and controls ( $11.5 \pm 3.75$ vs. $11.2 \pm 2.58$ years, $p=0.703)$. Regarding lipid profile, the median triglycerides [80(31-340) Vs. 61(19-182)mg/dL,p $=0.011]$ and VLDL[16(6-68) vs. $13(4-36) \mathrm{mg} / \mathrm{dL}, p=0.020$ ] were significantly higher in JDM patients versus controls. Gingival vasculopathy pattern was significantly higher in the former group $(60 \%$ vs. $0 \%, p=0.0001)$, as well as the median of gingival bleeding index (GBI) [24.1(4.2-69.4) vs. 11.1(0-66.6)\%, $p=0.001]$ and probing pocket depth (PPD) [1.7(0.6-2.4) vs.1.4(0-2.12) $\mathrm{mm}, p=0.006]$. Comparison between JDM patients with and without dyslipidemia revealed that the median of dental plaque index (PI) $[100(26.7-100)$ vs. $59(25-100) \%, p=0.022]$, PPD [1.9(0.6-2.4) vs. 1.4(1.2-1.8) $\mathrm{mm}, p=0.024]$ and clinical attachment level (CAL) [1.31(0.7-1.7) vs. 0.8(0.6-1.7) $\mathrm{mm}, p=0.005]$ were significantly higher in patients with dyslipidemia. Further analysis between JDM patients with and without gingivitis revealed that the median of current age [12.4 (8.3-18.4) vs. 9.2 (5.5-17.5) years, $p=0.034]$ and disease duration [7.09 \pm 3.07 vs. $3.95 \pm 2.1$ years, $p=0.008]$ were significantly higher in the former group.

Conclusion: Our study showed that gingival inflammation seems to be related to dyslipidemia in JDM patients, suggesting underlying mechanisms for both complications.

Keywords: Juvenile dermatomyositis, Dyslipidemia, Periodontal disease, Gingivitis

\section{Background}

Juvenile dermatomyositis (JDM) is a multisystemic disease of unknown etiology characterized by chronic inflammation of striated muscles and skin $[1,2]$. The survival rate, outcome and health related quality of life of JDM populations has been improving in the last years and some aspects, such as periodontal diseases [3, 4] and dyslipidemia [5-9] are particularly relevant for these patients.

Periodontal disease comprises gingivitis and periodontitis. It is defined as an immune inflammatory periodontal

\footnotetext{
* Correspondence: katia.kozu@hc.fm.usp.br; katia_kozu@hotmail.com

${ }^{1}$ Pediatric Rheumatology Unit, Hospital das Clinicas HCFMUSP, Faculdade de Medicina, Universidade de Sao Paulo, Rua Joel Jorge de Melo, 600 apto 121, Vila Mariana, São Paulo, SP 04128-081, Brazil

Full list of author information is available at the end of the article
}

disorder characterized by chronic localized infections associated with inflammation [3]. Periodontitis is a progressive phenomenon, beginning with gingivitis, followed by the destruction of the periodontal ligaments and bone reabsorption and ending in dental attachment loss [4]. Gengivitis and/or periodontitis have been seldom studied in pediatric autoimmune diseases, like juvenile idiopathic arthritis and juvenile systemic lupus erythematosus [10-15] Recently the association between periodontal disease and dyslipidemia was reported in healthy adults [16].

Data of gingivitis and periodontal diseases are scarce in JDM patients. Of note, the association between gingival vasculopathy pattern, characterized by gingival erythema, capillary dilation and bush-loop formation and disease

(c) The Author(s). 2018 Open Access This article is distributed under the terms of the Creative Commons Attribution 4.0 International License (http://creativecommons.org/licenses/by/4.0/), which permits unrestricted use, distribution, and 
activity was previously suggested $[4,17]$. Moreover, dyslipidemia has been rarely reported in JDM patients [5-9], and was observed in 36\% of JDM patients, characterized by low high-density lipoprotein (HDL) and high triglycerides (TG) levels [9].

However, to our knowledge, a systematic evaluation of concomitant periodontal diseases and lipid profile assessment was not carried out in JDM population.

Therefore, the aims of this study were to assess periodontal involvement and lipid profile in JDM patients and healthy controls, and to evaluate the possible associations between periodontal disease and dyslipidemia in this chronic inflammatory myopathy.

\section{Materials and methods}

\section{JDM patients and controls}

A cross-section study was performed from January 2009 to January 2011, and involved 52 JDM patients who were followed at the Pediatric Rheumatology Unit of our University Hospital. All of them fulfilled Bohan and Peter criteria for JDM diagnosis [18]. Exclusion criteria were: diabetes mellitus (fasting glycemia $>126 \mathrm{mg} / \mathrm{dL}$ ); renal insufficiency (creatinine clearance $<70 \mathrm{ml} / \mathrm{min} / 1.73 \mathrm{~m}^{2}$ ); proteinuria $>0.3 \mathrm{~g} / 24 \mathrm{~h}$; liver and thyroid dysfunction; neoplasia; infection in the last 15 days; hospitalization in the last month; previous/current smoking and alcohol use; current pregnancy; hormonal therapy; presence of orthodontic appliances and the use of lipid-lowering, anticonvulsant and antihypertensive drugs (thiazide, diuretics or betablockers). Twenty-seven JDM patients were excluded due to refusal to participate in this study $(n=20)$, presence of orthodontic appliances $(n=4)$ and incomplete evaluation $(n=3)$. Therefore, the final group was comprised by 25 JDM patients.

The healthy control group included 25 children and adolescents recruited from the families of JDM patients (either cousins or siblings) in order to minimize differences in some interfering aspects such as nutrition, constitutional and genetic factors. This study was approved by the Local Ethics Committee of our University Hospital and an age-appropriate written informed consent was obtained from all participants and their legal guardians.

\section{Methods}

\section{Demographic, anthropometric data and body composition}

Current age and gender were recorded for all subjects. For JDM patients, age at disease onset, and disease duration were also studied. Anthropometric data of patients and controls included blood pressure, weight in kilograms, height in meters, and body mass index (BMI) defined by the formula weight/height ${ }^{2}\left(\mathrm{~kg} / \mathrm{m}^{2}\right)$. For measurement of body composition, fat and lean mass and fat percentage were evaluated by dual-energy $\mathrm{x}$-ray absorptiometry
(DXA) using the densitometer Hologic QDR 4500 with pediatric software (Discovery model; Hologic Inc. Bedford, MA, USA). A questionnaire of life style/life habits was applied to all JDM patients and healthy controls to assess information regarding breastfeeding, weekly physical activity in hours, and familial history of coronary disease and dyslipidemia [9].

\section{Clinical evaluation and treatment}

All JDM patients were examined by the same pediatric rheumatologist to assess the following disease parameters scores: Disease Activity Score (DAS) [19], Childhood Myositis Assessment Scale (CMAS) [20], Manual Muscle Testing (MMT) [20], Myositis Disease Activity Assessment Analogue Scale (MYOACT) [21] and Myositis Intention to Treat Activity Index (MYTAX) [21]. Functional ability score was assessed according to the validated Brazilian version of Childhood Health Assessment Questionnaire (CHAQ) [22].

Current use and cumulative dose of prednisone, hydroxychloroquine, immunosuppressive drugs (methotrexate, cyclosporine, azathioprine and cyclophosphamide) were also determined.

\section{Periodontal assessment}

Periodontal assessment was performed in all subjects by three standardized epidemiological parameters: gingival index (GI), dental plaque index (PI) [23] and gingival bleeding index (GBI) [24]. Clinical dental attachment was evaluated by three other indices: probing pocket depth (PPD), cementoenamel junction (CEJ) and clinical attachment level (CAL), at six sites per tooth [25]. The number of decayed, missing and filled teeth (DMF-T) was also counted [26]. PI was used to evaluate the level of oral hygiene, which was calculated according to the number of dental surfaces stained by a dental plaque disclosing agent, multiplied by 100 and divided by the total number of surfaces [23]. GBI was used to evaluate gingival inflammation, and was expressed as the number of bleeding surfaces after probing with a periodontal probe, which was then multiplied by 100 and divided by the total number of surfaces [24]. PPD was determined as the distance from the bottom of the pocket to the gingival margin (normal range $<3 \mathrm{~mm}$ ). CEJ was measured as the distance from the gingival margin to the cementoenamel junction, identifying hyperplasia or recession. CAL was calculated as the sum of PPD and CEJ (normal range $<3 \mathrm{~mm}$ ) [25]. Gingivitis was defined as inflammation of the gingiva in the absence of clinical attachment loss [27] with $\mathrm{GBI}>25 \%$ [28]. Gingival vasculopathy pattern was defined according to the presence of concomitant gingival erythema, capillary dilation and bush-loop formation pattern, as previously described [3]. 


\section{Laboratory analysis}

Biochemical analyses were performed for JDM patients and controls on serum samples obtained after 12-h over-night fasting at the study entry.

\section{Lipid profile}

Total cholesterol (TC) and triglycerides (TG) were measured enzymatically on a Technicom RA 1000 System analyser (Boehringer Mannheim, Argentina and Merck, Alemanha) [29, 30]. High-density lipoprotein (HDL) cholesterol was obtained by colorimetric method (Roche
Diagnostics) after precipitation of very low-density lipoprotein (VLDL) cholesterol and low-density lipoprotein (LDL) cholesterol by phosphotungstic acid and magnesium chloride [31]. Levels of VLDL were estimated using the formula of TG levels divided by 5 (TG/5), since all samples had a TG level $<400 \mathrm{mg} / \mathrm{dL}$ [32]; and LDL cholesterol levels were estimated using the following equation: TC - (HDL + VLDL) [32]. Normal values were defined according to national norms for metabolic data for children and adolescents as follow: $\mathrm{TC} \leq 170 \mathrm{mg} / \mathrm{dL}$, $\mathrm{HDL} \geq 45 \mathrm{mg} / \mathrm{dL}, \mathrm{LDL} \leq 130 \mathrm{mg} / \mathrm{dL}$, and $\mathrm{TG} \leq 130 \mathrm{mg} /$

Table 1 Demographic and anthropometric data, body composition, laboratorial findings and periodontal evaluation in juvenile dermatomyositis (JDM) patients and healthy controls

\begin{tabular}{|c|c|c|c|}
\hline Variables & JDM patients $(n=25)$ & Controls $(n=25)$ & $p$ \\
\hline \multicolumn{4}{|l|}{ Demographic data } \\
\hline Current age, years & $11.5 \pm 3.75$ & $11.2 \pm 2.58$ & 0.703 \\
\hline Female gender & $14(56)$ & $13(52)$ & 0.500 \\
\hline \multicolumn{4}{|l|}{ Anthropometric data } \\
\hline $\mathrm{BMl}, \mathrm{kg} / \mathrm{m}^{2}$ & $19.1(12.7-30)$ & $17.1(14.4-27.5)$ & 0.954 \\
\hline Systolic blood pressure, $\mathrm{mmHg}$ & $90(80-118)$ & $90(80-110)$ & 0.099 \\
\hline Dyastolic blood pressure, $\mathrm{mmHg}$ & $60(50-85)$ & $60(45-70)$ & 0.211 \\
\hline \multicolumn{4}{|l|}{ Body composition } \\
\hline Fat percentage & $27.5(10.9-45.4)$ & $22.5(10.2-42.3)$ & 0.230 \\
\hline Fat mass, kg & $10.7(2.9-27.1)$ & $6.7(2.8-30.5)$ & 0.274 \\
\hline Lean mass, kg & $24.8 \pm 6.4$ & $25.4 \pm 7.6$ & 0.599 \\
\hline \multicolumn{4}{|l|}{ Lipid profile } \\
\hline Dyslipidemia & $17(68)$ & $10(40)$ & 0.087 \\
\hline Total cholesterol & $151(102-227)$ & $151(121-207)$ & 0.941 \\
\hline$\geq 170 \mathrm{mg} / \mathrm{dL}$ & $8(32)$ & $4(16)$ & 0.320 \\
\hline $\mathrm{HDL}, \mathrm{mg} / \mathrm{dL}$ & $44(0-72)$ & $50(30-65)$ & 0.117 \\
\hline$\leq 45 \mathrm{mg} / \mathrm{dL}$ & $10(40)$ & $7(28)$ & 0.550 \\
\hline $\mathrm{LDL}, \mathrm{mg} / \mathrm{dL}$ & $87(56-148)$ & $91(54-140)$ & 0.675 \\
\hline$\geq 130 \mathrm{mg} / \mathrm{dL}$ & $1(4)$ & $2(8)$ & 1.000 \\
\hline$V L D L, m g / d L$ & $16(6-68)$ & $13(4-36)$ & 0.020 \\
\hline Triglycerides, mg/dL & $80(31-340)$ & $61(19-182)$ & 0.011 \\
\hline$\geq 130 \mathrm{mg} / \mathrm{dL}$ & $5(20)$ & $1(4)$ & 0.189 \\
\hline Anti-LPL antibody & $1(4)$ & 0 & 1.000 \\
\hline \multicolumn{4}{|l|}{ Periodontal assessment } \\
\hline Gingival vasculopathy pattern & $15(60)$ & $0(0)$ & 0.0001 \\
\hline DMF-T & $2(0-5)$ & $2(0-3)$ & 0.862 \\
\hline $\mathrm{Pl}, \%$ & $90.6(25-100)$ & $71.5(19.8-100)$ & 0.051 \\
\hline $\mathrm{GBI}, \%$ & $24.1(4.2-69.4)$ & $11.1(0-66.6)$ & 0.001 \\
\hline PPD, mm & $1.7(0.6-2.4)$ & $1.4(0-2.12)$ & 0.006 \\
\hline CEJ, mm & $-0.1(-0.8-0)$ & $-0.1(-0.9-0)$ & 0.570 \\
\hline $\mathrm{CAL}, \mathrm{mm}$ & $1.25(0.7-1.7)$ & $1(0.6-1.7)$ & 0.071 \\
\hline
\end{tabular}

Values expressed in mean \pm SD, median (range) and $n$ (\%); BMI (body mass index), HDL (high density lipoprotein), $L D L$ (low density lipoprotein), VLDL (very low density), anti-LPL (anti-lipoprotein lipase antibody), DMF-T (decayed, missing and filled tooth index), PI (plaque index), GBI (gingival bleeding index), PPD (probing pocket depth), CEJ (cementoenamel juntion), CAL (clinical attachment level) 
dL [33]. Dyslipidemia was defined when subjects presented lipid abnormalities in at least one of these lipid parameters [33].

\section{Anti-lipoprotein lipase (LPL) antibodies}

Anti-LPL IgG isotype antibodies were measured by double-enzyme-linked immunosorbent assay (ELISA). Costar polystyrene plates were coated overnight with commercially available LPL from bovine milk $(5 \mu \mathrm{g} / \mathrm{ml}$; Sigma, St Louis, MO) and then blocked with 15\% adult bovine serum in Tris buffered saline (ABS-T) for one hour at room temperature. The test was performed with serum samples diluted at 1:100 in ABS-T incubated for one hour at room temperature. Anti-LPL IgG isotype antibodies were determined by alkaline phosphatase conjugated goat anti-human IgG (Sigma). The reaction was developed by means of p-nitrophenylphosphate and optical density (OD) was read at $405 \mathrm{~nm}$ with a labsystems Multiskan MS (Labsystems, Helsinki, Finland). Positive results were defined as OD values $\geq 3$ standard deviation (SD) above the mean OD values of the 25 healthy control serum samples (cut-off value 0.36). To ensure consistency between assays, serial dilutions of known positive serum samples were included in each study [34].

\section{Inflammatory profile and muscle enzymes}

The following tests were performed in JDM patients only. Erythrocyte sedimentation rate (ESR) was evaluated using the Westergren method and C-reactive protein (CRP) by nephelometry. Skeletal muscle enzymes included creatinine kinase (CK) and aldolase measured by kinetic automated method, and lactate dehydrogenase
$(\mathrm{LDH})$, aspartate aminotransferase (AST) and alanine aminotransferase (ALT) by kinetic method.

\section{Statistical analysis}

Data were presented in median (range) or mean $( \pm \mathrm{SD})$ for continuous variables according to abnormal or normal distribution, respectively. Data were presented in number (percentage) for categorical variables. For continuous variables data were compared using Mann-Whitney test or $\mathrm{t}$ test to evaluate differences between JDM patients and controls, JDM patients with and without gingivitis, and also JDM patients with and without dyslipidemia according to demographic, anthropometric, laboratorial, treatments and dental parameters. For categorical variables, differences were assessed by Fisher exact test. $P$-values $<0.05$ were considered as significant.

\section{Results}

JDM patients vs. healthy controls

Demographic, anthropometric data, body composition, laboratorial exams and periodontal evaluation in JDM patients and healthy controls are shown in Table 1. The mean of current age was similar in JDM patients and healthy controls $(11.5 \pm 3.75$ vs. $11.2 \pm 2.58$ years, $p=0.703)$. Although trend of a higher frequency of dyslipidemia was observed in JDM patients compared to controls [68\% vs. $40 \%, p=0.087$ ] it was not statistically significant. The median TG [80 (31-340) vs. 61 (19-182) $\mathrm{mg} / \mathrm{dL}, p=0.011]$ and VLDL [16 (6-68) vs. $13(4-36) \mathrm{mg} / \mathrm{dL}, p=0.020$ ] were significantly higher in JDM patients versus controls. The frequency of gingival vasculopathy pattern was significantly higher in the former group ( $60 \%$ vs. $0 \%, p=0.0001)$, as well as

Table 2 Demographic data and periodontal assessment in juvenile dermatomyositis (JDM) patients with and without dyslipidemia

\begin{tabular}{llll}
\hline Variables & JDM with dyslipidemia $(n=17)$ & JDM without dyslipidemia $(n=8)$ & \\
\hline Demographic data & & & \\
Current age, years & $12.2(5.5-18.4)$ & $8.5(7.2-17.8)$ & 0.103 \\
Age at disease presentation, years & $6.56 \pm 2.73$ & $4.83 \pm 2.46$ & 0.159 \\
Disease duration, years & $5.49 \pm 3.45$ & $5.2 \pm 1.55$ & 0.840 \\
Female gender & $9(52)$ & & 1.000 \\
Periodontal assessment & & $4(50)$ & $2(25)$ \\
Gingival vasculopathy pattern & $11(64)$ & $1(0-6)$ & 0.667 \\
Gingivitis (GBI > 25\%) & $10(59)$ & $59(25-100)$ & 0.202 \\
DMF-T & $2(0-12)$ & $19.6(13-50)$ & 0.102 \\
PI, \% & $100(26.7-100)$ & $1.4(1.2-1.8)$ & 0.022 \\
GBI, \% & $29.7(4.2-69.4)$ & $-0.1(-0.5-0.04)$ & 0.923 \\
PPD, mm & $1.9(0.6-2.4)$ & $0.8(0.6-1.7)$ & 0.024 \\
CEJ, mm & $-0.12(-0.8-0)$ & 0.923 \\
CAL, mm & $1.31(0.7-1.7)$ & 0.005 \\
\hline
\end{tabular}

Values expressed in mean \pm SD, median (range) and $n$ (\%); GBI (gingival bleeding index), DMF-T (decayed, missing, filled teeth index), $P$ (plaque index), PPD (probing pocket depth), CEJ (cementoenamel juntion), CAL (clinical attachment level) 
Table 3 Demographic and anthropometric data, body composition, laboratorial findings, juvenile dermatomyositis (JDM) scores and treatment in JDM patients with and without gingivitis

\begin{tabular}{|c|c|c|c|}
\hline Variables & $J D M$ with gingivitis $(G B I>25 \%, n=12)$ & $J D M$ without gingivitis $(G B I \leq 25 \%, n=12)$ & $p$ \\
\hline \multicolumn{4}{|l|}{ Demographic data } \\
\hline Current age, years & $12.4(8.3-18.4)$ & $9.2(5.5-17.5)$ & 0.034 \\
\hline Age at disease presentation, years & $4.8(3.7-7.4)$ & $5.2(4.1-9.5)$ & 0.580 \\
\hline Disease duration, years & $7.09 \pm 3.07$ & $3.95 \pm 2.1$ & 0.008 \\
\hline Female gender & $9(75)$ & $5(41)$ & 0.182 \\
\hline \multicolumn{4}{|l|}{ Anthropometric data } \\
\hline $\mathrm{BMl}, \mathrm{kg} / \mathrm{m}^{2}$ & $19.6(14.5-30)$ & $19.2(15.3-25)$ & 0.954 \\
\hline \multicolumn{4}{|l|}{ Body composition } \\
\hline Fat percentual & $28.2(11.1-45.4)$ & $26(10.9-42)$ & 0.789 \\
\hline Fat mass, kg & $10.8(5.0-27.1)$ & $8.2(2.9-20.2)$ & 1.000 \\
\hline Lean mass, kg & $26.4(15.4-43.8)$ & $27.2(20-44.5)$ & 0.423 \\
\hline \multicolumn{4}{|l|}{ Lipid profile } \\
\hline Total cholesterol & $151(115-206)$ & $151(102-227)$ & 0.913 \\
\hline$\geq 170 \mathrm{mg} / \mathrm{dL}$ & $5(41)$ & $3(25)$ & 0.666 \\
\hline $\mathrm{HDL}, \mathrm{mg} / \mathrm{dL}$ & $43(0-65)$ & $49(17-72)$ & 0.328 \\
\hline$\leq 45 \mathrm{mg} / \mathrm{dL}$ & $9(75)$ & $4(33)$ & 0.099 \\
\hline $\mathrm{LDL}, \mathrm{mg} / \mathrm{dL}$ & $92(76-148)$ & 77.5 (56-129) & 0.265 \\
\hline$\geq 130 \mathrm{mg} / \mathrm{dL}$ & $1(9)$ & 0 & 1.000 \\
\hline VLDL, mg/dL & $16(9-42)$ & $14.5(9-68)$ & 0.957 \\
\hline Triglycerides, mg/dL & $82(31-168)$ & $72.5(46-340)$ & 0.935 \\
\hline$\geq 130 \mathrm{mg} / \mathrm{dL}$ & $1(8)$ & $3(33)$ & 0.316 \\
\hline Anti-LPL antibody & 0 & $1(8)$ & 1.000 \\
\hline \multicolumn{4}{|l|}{ Muscle enzymes } \\
\hline AST, U/L & $28(13-122)$ & $29.5(15-82)$ & 0.703 \\
\hline$A L T, U / L$ & $36(22-123)$ & $34(29-79)$ & 0.744 \\
\hline CK, U/L & $84(33-478)$ & $125(62-179)$ & 0.399 \\
\hline $\mathrm{LDH}, \mathrm{U} / \mathrm{L}$ & $184(107-1234)$ & $216.5(153-562)$ & 0.355 \\
\hline Aldolase, U/L & $5.7(3.4-10.8)$ & $6.35(4.6-14.6)$ & 0.231 \\
\hline \multicolumn{4}{|l|}{ Inflammatory profile } \\
\hline $\mathrm{ESR}, \mathrm{mm} / 1^{\mathrm{ST}}$ hour & $20(2-40)$ & $19(7-54)$ & 0.624 \\
\hline $\mathrm{CRP}, \mathrm{mg} / \mathrm{dL}$ & $0.59(0.16-5.5)$ & $1.61(0.15-26)$ & 0.242 \\
\hline \multicolumn{4}{|l|}{ JDM scores } \\
\hline CMAS, $0-52$ & $52(10-52)$ & $52(17-52)$ & 0.848 \\
\hline MMT, 0-80 & $80(42-80)$ & $80(38-80)$ & 0.742 \\
\hline DAS, 0-18 & $4(0-12)$ & $3(0-18)$ & 0.807 \\
\hline Cutaneous DAS, 0-9 & $1(0-8)$ & $1(0-9)$ & 0.663 \\
\hline Muscle DAS & $2(0-9)$ & $2(0-9)$ & 0.853 \\
\hline MYOACT, 0-1 & $0.05(0-0.16)$ & $0.02(0-0.3)$ & 0.724 \\
\hline MITAX, 0-1 & $0.01(0-0.23)$ & $0(0-0.28)$ & 0.462 \\
\hline CHAQ & $0(0-1.75)$ & $0.625(0-2.5)$ & 0.164 \\
\hline \multicolumn{4}{|l|}{ Treatment } \\
\hline \multicolumn{4}{|l|}{ Prednisone } \\
\hline Current use & $1(8)$ & $8(66)$ & 0.303 \\
\hline
\end{tabular}


Table 3 Demographic and anthropometric data, body composition, laboratorial findings, juvenile dermatomyositis (JDM) scores and treatment in JDM patients with and without gingivitis (Continued)

\begin{tabular}{|c|c|c|c|}
\hline Variables & JDM with gingivitis $(G B I>25 \%, n=12)$ & $J D M$ without gingivitis $(G B I \leq 25 \%, n=12)$ & $p$ \\
\hline Cumulative dose, $\mathrm{g}$ & $13.6(4.9-51.5)$ & $15.1(3.9-31.2)$ & 0.531 \\
\hline \multicolumn{4}{|l|}{ Methotrexate } \\
\hline Current use & $3(25)$ & $8(66)$ & 0.277 \\
\hline Cumulative dose, $\mathrm{g}$ & $2.2(0.3-16.9)$ & $1.9(0.37-4.98)$ & 0.79 \\
\hline \multicolumn{4}{|l|}{ Cyclosporine } \\
\hline Current use & 0 & $3(25)$ & 0.230 \\
\hline Cumulative dose, $\mathrm{g}$ & $0(0-3.6)$ & 0 & 0.805 \\
\hline
\end{tabular}

Values expressed in mean $\pm S D$, median (range) and $n$ (\%), GBI (gingival bleeding index), BMI (body mass index), $H D L$ (high density lipoprotein), $L D L$ (low density lipoprotein), VLDL (very low density), anti-LPL (anti-lipoprotein lipase antibody), AST (aspartate aminotransferase), ALT (alanine aminotransferase), CK (creatine kinase), LDH (lactate dehydrogenase), ESR (erythrocyte sedimentation rate), CRP (C-reactive protein), CMAS (Childhood Myositis Assessment Scale), MMT (Manual Muscle Testing), DAS (Disease Activity Score), MYOACT (Myositis Disease Activity Assessment Analogue Scale), MYTAX (Myositis Intention To Treat Activity Index), CHAQ (childhood assessment questionnaire)

the median of GBI $[24.1(4.2-69.4)$ vs. $11.1(0-66.6) \%$, $p=0.001]$ and PPD $[1.7(0.6-2.4)$ vs. $1.4(0-2.12) \mathrm{mm}$, $p=0.006]$ (Table 1).

No differences were observed in breastfeeding duration [4 (0-7) vs. $3(0-12)$ months, $p=0.548$ ], weekly physical activity $[4(0-14)$ vs. 5 (5-30), hours, $p=$ 0.182 ] and familial history of coronary disease $(32 \%$ vs. $52 \%, p=0.251$ ) between JDM patients and healthy controls.

Periodontal assessment and dyslipidemia in JDM patients Further analysis between JDM patients with and without dyslipidemia revealed that the median of PI [100 (26.7-100) vs. 59 (25-100)\%, $p=0.022]$, PPD [1.9 (0.6$2.4)$ vs. $1.4(1.2-1.8) \mathrm{mm}, p=0.024]$ and CAL [1.31 $(0.7-1.7)$ vs. $0.8(0.6-1.7) \mathrm{mm}, p=0.005]$ were significantly higher in JDM patients with dyslipidemia compared to those without this complication (Table 2).

Gingivitis (GBI > 25\%) was observed in 12/24 (50\%) of JDM patients and $9 / 12$ (75\%) had concomitantly gingivitis with gingival vasculopathy pattern that extends over the upper and/or lower teeth. Further analysis between JDM patients with and without gingivitis revealed that the median of current age $[12.4(8.3-18.4)$ vs. $9.2(5.5-17.5)$ years, $p=0.034]$ and disease duration [7.09 \pm 3.07 vs. 3.95 \pm 2.1 years, $p=0.008$ ] were significantly higher in the former group. No differences were observed in BMI, body composition, anti-LPL antibodies, muscle enzymes, inflammatory parameters, JDM scores and treatments in both groups (Table 3). None of the patients were classified as presenting lipodystrophy (data not shown).

\section{Discussion}

According to our study, gingival inflammation seems to be related to dyslipidemia in JDM patients, suggesting common underlying mechanisms for both complications.

The great advantage of the study was to assess a concomitant evaluation of periodontal and lipid parameters in JDM patients and healthy controls. Tobacco use, alcohol intake, diabetes mellitus and some medications may be related to periodontal disorders and therefore they were considered as exclusion criteria [13]. Moreover, the control group included only JDM siblings or relatives, to minimize risk factors associated with periodontal diseases and dyslipidemia, particularly tooth brushing habits, nutrition and genetic factors. However, the major limitations of the present study were a relative small sample, due to the restricted inclusion and exclusion criteria, and a cross-sectional study design.

We confirmed previous evidences of altered lipid profile in JDM populations [5-9]. Dyslipidemia occurred in approximately $70 \%$ of our JDM patients, with high levels of VLDL and triglycerides. The presence of anti-LPL antibodies, a specific autoantibody associated with hypertriglyceridemia in systemic lupus erythematosus patients [34], was not a possible explanation for the lipoprotein abnormalities seen in our JDM patients.

The gingival inflammation, that used to be considered a process restricted to oral cavity, can now be considered as responsible for systemic inflammation and associated to disease activity in children [4] and adult patients [35]. It is believed that in predisposed individuals, a metastatic inflammation can occur, that is, a systemic inflammatory reaction to the presence of microorganisms (aerobic and anaerobic bacteria) in the chronically inflamed gingiva and periodontal ligaments. Thus, in the presence of gingivitis or periodontitis, inflammatory cytokines such as IL1 and IL6 are produced and exert local and systemic action, leading to an increase in circulating immune complexes. Therefore, periodontal abnormalities could act as a trigger for local and systemic inflammatory process, which in turn predisposes to metabolic changes, explaining the association between the expressive plaque indexes found in our patients with JDM with dyslipidemia [16, 36].

In addition, three-quarter of our JDM patients with gingivitis (gingival bleeding index $>25 \%$ ) had a concomitant 
clinical gingival vasculopathy pattern that extends over the upper and/or lower teeth, indicating a diffuse oral involvement. Of note, gingival alterations were not associated with treatment particularly with glucocorticoid and cyclosporine. This latter immunosuppressive drug is a well-known cause of gingival enlargement [37]. Moreover, gingival alterations could not be attributed to disease activity, since it was similar in JDM patients with and without gingivitis, with both groups presenting inactive disease or mild to moderate disease activity.

It was observed, however, that the group of patients with JDM and gingival alterations was composed by older individuals with longer disease duration. This fact suggests that the persistence of a chronic inflammatory process related to JDM disease could be responsible for the greater periodontal involvement and reinforces that periodontitis is a progressive phenomenon, beginning with gingivitis, followed by the destruction of the periodontal ligaments and bone reabsorption and ending in dental attachment loss [4]. In fact, although initial aspects of periodontitis, such as increased PCS and PCI, were associated with patients with JDM and dyslipidemia, none of the patients studied was classified as having periodontitis $(\mathrm{PCI}>3 \mathrm{~mm})$, which is rarely observed in pediatric age group [15]. Future prospective studies should be necessary to clarify this point.

The worst oral hygiene observed in the group of JDM patients with abnormal lipid profile alert to the risk of bacterial plaque accumulation inducing local inflammatory process, a condition that could contribute to aggravate periodontal and systemic inflammation, leading to lipid changes and increased risk of coronary artery diseases. Therefore, it is necessary to encourage patients and family members to maintain an adequate oral health $[4,36]$.

\section{Conclusions}

Gingival inflammation and attachment loss observed in the studied sample were associated with dyslipidemia and dental changes were more evident the longer was the disease duration.

Gingivitis and poor oral hygiene are important concerns in JDM dyslipidemic patients, especially after long-term disease. These findings indicate the importance of oral health prevention and treatment for these patients, aiming to reduce their early cardiovascular risk.

\section{Acknowledgements}

We thank Prof. Dr. Jose Siqueira Tadeu and Dr. Priscila Ribas Guardieiro for their suggestions and comments, and Dr. Ulysses Doria Filho for statistical analysis.

\section{Funding}

This study was supported by grants from Fundação de Amparo à Pesquisa do Estado de São Paulo (FAPESP 2008/58238-4 to CAS), Conselho Nacional de Desenvolvimento Científico e Tecnológico (CNPq 303422/2015-7 to CAS and 301805/2013-0 to RMRP), Federico Foundation (to CAS and RMRP) and by Núcleo de Apoio à Pesquisa "Saúde da Criança e do Adolescente" of Universidade de São Paulo (NAP-CriAd) to CAS

\section{Authors' contributions}

All authors contributed equally to this paper. All authors read and approved the final manuscript

\section{Ethics approval and consent to participate}

This study was approved by the Local Ethics Committee of our University Hospital and an age-appropriate written informed consent was obtained from all participants and their legal guardians.

\section{Consent for publication}

The consent for publication was also obtained from patient's parents or their legal guardian.

\section{Competing interests}

The authors declared that they have no competing interests.

\section{Publisher's Note}

Springer Nature remains neutral with regard to jurisdictional claims in published maps and institutional affiliations.

\section{Author details}

${ }^{1}$ Pediatric Rheumatology Unit, Hospital das Clinicas HCFMUSP, Faculdade de Medicina, Universidade de Sao Paulo, Rua Joel Jorge de Melo, 600 apto 121, Vila Mariana, São Paulo, SP 04128-081, Brazil. ²Division of Rheumatology, Hospital das Clinicas HCFMUSP, Faculdade de Medicina, Universidade de Sao Paulo, São Paulo, SP, Brazil. ${ }^{3}$ Division of Dentistry, Hospital das Clinicas HCFMUSP, Faculdade de Medicina, Universidade de Sao Paulo, São Paulo, SP Brazil.

Received: 11 July 2018 Accepted: 31 July 2018

Published online: 05 September 2018

\section{References}

1. Sato JO, Sallum AM, Ferriani VP, Marini R, Sacchetti SB, Okuda EM, et al. A Brazilian registry of juvenile dermatomyositis: onset features and classification of 189 cases. Clin Exp Rheumatol. 2009;27:1031-8.

2. Aikawa NE, Jesus AA, Liphaus BL, Silva CA, Carneiro-Sampaio M, Viana VS, et al. Organ-specific autoantibodies and autoimmune diseases in juvenile systemic lupus erythematosus and juvenile dermatomyositis patients. Clin Exp Rheumatol. 2012;30:126-31.

3. Savioli C, Silva CA, Fabri GM, Kozu K, Campos LM, Bonfá E, et al. Gingival capillary changes and oral motor weakness in juvenile dermatomyositis. Rheumatology (Oxford). 2010;49:1962-70.

4. Fabri GM, Savioli C, Siqueira JT, Campos LM, Bonfá E, Silva CA. Periodontal disease in pediatric rheumatic diseases. Rev Bras Reumatol. 2014;54:311-7.

5. Huemer C, Kitson H, Malleson PN, Sanderson S, Huemer M, Cabral DA, et al. Lipodystrophy in patients with juvenile dermatomyositis - evaluation of clinical and metabolic abnormalities. J Rheumatol. 2001;28:610-5.

6. Verma S, Singh S, Bhalla AK, Khullar M. Study of subcutaneous fat in children with juvenile dermatomyositis. Arthritis Rheum. 2006;55:564-8.

7. Bingham A, Mamyrova G, Rother Kl, Oral E, Cochran E, Premkumar A, et al. Predictors of acquired lipodystrophy in juvenile-onset dermatomyositis and a gradient of Medicine (Baltimore). 2008;87:70-86.

8. Coyle K, Rother Kl, Weise M, Ahmed A, Miller FW, Rider LG. Metabolic abnormalities and cardiovascular risk factors in children with myositis. J Pediatr. 2009;155:882-7.

9. Kozu KT, Silva CA, Bonfá E, Sallum AM, Pereira RM, Viana VS, et al. Dyslipidaemia in juvenile dermatomyositis: the role of disease activity. Clin Exp Rheumatol. 2013;31:638-44.

10. Savioli C, Silva CA, Siqueira JT. Características morfológicas e funcionais do sistema estomatognático em pacientes portadores de artrite reumatóide juvenil. J Bras Ortodon Ortop Facial. 2000:25:70-8.

11. Savioli C, Silva CA, Ching LH, Campos LM, Prado EF, Siqueira JT. Dental and facial characteristics of patients with juvenile idiopathic arthritis. Rev Hosp Clin Fac Med Sao Paulo. 2004;59(3):93-8.

12. Fernandes EG, Savioli C, Siqueira JT, Silva CA. Oral health and the masticatory system in juvenile systemic lupus erythematosus. Lupus. 2007;16:713-9. 
13. Pugliese C, van der Vinne RT, Campos LM, Guardieiro PR, Saviolli C, Bonfá E, et al. Juvenile idiopathic arthritis activity and function ability: deleterious effects in periodontal disease? Clin Rheumatol. 2016;35:81-91.

14. Figueredo CM, Areas A, Sztajnbok FR, Miceli V, Miranda LA, Gustafsson A. Higher elastase activity associated with lower IL-18 in GCF from juvenile systemic lupus patients. Oral Health Prev Dent. 2008;6:75-81.

15. Sete MR, Figueredo CM, Sztajnbok F. Periodontitis and systemic lupus erythematosus. Rev Bras Reumatol. 2016;56:165-70.

16. Jaramillo A, Lafaurie Gl, Millán LV, Ardila CM, Duque A, Novoa C, et al. Association between periodontal disease and plasma levels of cholesterol and triglycerides. Colomb Med (Cali). 2013:44:80-6.

17. Rider $L G$, Atkinson JC. Images and clinical medicine: gingival and periungual vasculopathy of juvenile dermatomyositis. N Engl J Med. 2009:360:e21.

18. Bohan A, Peter JB. Polymyositis and dermatomyositis. N Engl J Med. 1975; 292:344-7.

19. Bode RK, Klein-Gitelman MS, Miller ML, Lechman TS, Pachman LM. Disease activity score for children with juvenile dermatomyositis: reliability and validity evidence. Arthritis Rheum. 2003:49:7-15.

20. Lovell DJ, Lindsley CB, Rennebohm RM, Ballinger SH, Bowyer SL, Giannini $E H$, et al. Development of validated disease activity and damage indices for the juvenile idiopathic inflammatory myopathies. II. The childhood myositis assessment scale (CMAS): a quantitative tool for the evaluation of muscle function. The juvenile dermatomyositis disease activity collaborative study group. Arthritis Rheum. 1999:42:2213-9.

21. Sultan SM, Allen E, Oddis CV, Kiely P, Cooper RG, Lundberg IE, et al. Reliability and validity of the myositis disease activity assessment tool. ArthritisRheum. 2008;58:3593-9.

22. Machado CS, Ruperto N, Silva CH, Ferriani VP, Roscoe I, Campos LM, et al. Paediatric Rheumatology International Trials Organisation. The Brazilian version of the childhood health assessment questionnaire (CHAQ) and the child health questionnaire (CHQ). Clin Exp Rheumatol. 2001;23:25-9.

23. Ainamo J, Bay I. Problems and proposals for recording gingivitis and plaque. Int Dent J. 1975;25:229-35.

24. O'Leary TJ. The periodontal screening examination. J Periodontol. 1967;38: $617-24$

25. Armitage GC. American Academy of periodontology. Periodontol record Ann Periodontol. 1999:4:1-6.

26. World Health Organization. Oral health surveys: basic methods. 4th ed Geneva: World Health Organization; 1997.

27. Parameter on plaque-induced gingivitis. American Academy of Periodontology. J Periodontol. 2000;71:851-2.

28. Modéer T, Blomberg CC, Wondimu B, Julihn A, Marcus C. Association between obesity, flow rate of whole saliva, and dental caries in adolescents. Obesity. 2010:18:2367-73.

29. Fossati $P$, Prencipe L. Serum triglycerides determined colorimetrically with an enzyme that produces hydrogen peroxide. Clin Chem. 1982;28:2077-780.

30. Siedel J, Hägele EO, Ziegenhorn J, Wahlefeld AW. Reagent for the enzymatic determination of serum total cholesterol with improved lipolytic efficiency. Clin Chem. 1983;29:1075-80.

31. Warnick GR, Cheung MC, Albers JJ. Comparison of current methods for high - density lipoprotein cholesterol quantification. Clin Chem. 1979;25:596-604.

32. Friedewald WT, Levy RI, Fredrickson DS. Estimation of the concentration of low -density lipoprotein cholesterol in plasma, without use of the preparative ultracentrifuge. Clin Chem. 1972;18:499-502.

33. Xavier HT, Izar MC, Faria Neto JR, Assad MH, Rocha VZ, Sposito AC, et al. V Brazilian guidelines on dyslipidemias and prevention of atherosclerosis. Arq Bras Cardiol. 2013;101:1-20

34. De Carvalho JF, Borba EF, Viana VS, Bueno C, Leon EP, Bonfá E. Anti-lipoprotein lipase antibodies: a new player in the complex atherosclerotic process in systematic lupus erythematosus? Arthritis Rheum. 2004;50:3610-5.

35. Venkataraman A, Almas K. Rheumatoid arthritis and periodontal disease. N Y State Dent J. 2015;81:30-6

36. Noguchi E, Kato R, Ohno K, Mitsui A, Obama T, Hirano T, et al. The apolipoprotein B concentration in gingival crevicular fluid increases in patients with diabetes mellitus. Clin Biochem. 2014;47:67-71.

37. Shiboski CH, Krishnan S, Besten PD, Golinveaux M, Kawada P, Tornabene A et al. Gingival enlargement in pediatric organ transplant recipients in relation to tacrolimus-based immunosuppressive regimens. Pediatr Dent. 2009;31:38-46

\section{Ready to submit your research? Choose BMC and benefit from:}

- fast, convenient online submission

- thorough peer review by experienced researchers in your field

- rapid publication on acceptance

- support for research data, including large and complex data types

- gold Open Access which fosters wider collaboration and increased citations

- maximum visibility for your research: over $100 \mathrm{M}$ website views per year

At $\mathrm{BMC}$, research is always in progress.

Learn more biomedcentral.com/submissions 